\title{
Phosphorylated NiCo Metal-Organic-Frameworks for Efficient Oxygen Evolution Reaction
}

\author{
Meng Zong ${ }^{1, \#, *}$, Keke Wang ${ }^{2,3, \#}$, Zongshan Lin ${ }^{2,3}$ and Zhenghua Tang ${ }^{2 *}$ \\ ${ }^{1}$ Chongqing Chemical Industry Vocational College, Chongqing, 401220, China. \\ ${ }^{2}$ Guangzhou Key Laboratory for Surface Chemistry of Energy Materials and New Energy Research \\ Institute, School of Environment and Energy, South China University of Technology, Guangzhou \\ Higher Education Mega Centre, Guangzhou, 510006, China. \\ ${ }^{3}$ School of Pharmacy, Guangdong Pharmaceutical University, Guangzhou, 510006, China. \\ *E-mail: ahzmeng@126.com, zhht@ scut.edu.cn \\ \#These authors contributed equally.
}

Received: 1 xxx 2021 / Accepted: 16 June 2021 / Published: 10 August 2021

The development of abundant-element-based, cost-effective, and efficient catalysts for oxygen evolution reaction (OER) holds great promises to realize the practical water splitting. Herein, we report a facile phosphorylation treatment to boost the OER performance of NiCo metal organic frameworks (MOFs). Compared with the parent hollow bowl-like sphere NiCo-MOF, the optimal NiCo-MOF/Co $2 \mathrm{P}_{2} \mathrm{O}_{7}$ had a lower overpotential of $408 \mathrm{mV}$ at $50 \mathrm{~mA} \mathrm{~cm}{ }^{-2}$ and $583 \mathrm{mV}$ at $200 \mathrm{~mA} \mathrm{~cm}{ }^{-2}$. The $\mathrm{MOF} / \mathrm{Co}_{2} \mathrm{P}_{2} \mathrm{O}_{7} \mathrm{sample}$ also demonstrated markedly superior long term durability for OER to the benchmark $\mathrm{RuO}_{2}$ catalyst. Such excellent performance can be attributed to the well-defined porous structure imparted enhanced reaction kinetics, the formation of phosphates with high oxygen content, and the synergistic catalytic effects of between $\mathrm{Ni}$ and $\mathrm{Co}$. The findings here offer a new way in developing high-efficiency and durable MOF-based electrocatalysts for water splitting and beyond.

Keywords: Phosphorous treatment; NiCo alloy; Metal organic frameworks; Oxygen evolution reaction, Long term durability

\section{$\underline{\text { FULL TEXT }}$}

(C) 2021 The Authors. Published by ESG (www.electrochemsci.org). This article is an open access article distributed under the terms and conditions of the Creative Commons Attribution license (http://creativecommons.org/licenses/by/4.0/). 